\title{
Do remote dialysis services really cost more? An economic analysis of hospital and dialysis modality costs associated with dialysis services in urban, rural and remote settings
}

\author{
Gillian Gorham ${ }^{1 *} \mathbb{D}$, Kirsten Howard², Joan Cunningham', Federica Barzi ${ }^{1}$, Paul Lawton ${ }^{1}$ and Alan Cass ${ }^{1}$
}

\begin{abstract}
Background: Rates of end-stage kidney disease in Australia are highest in the Northern Territory (NT), with the burden of disease heaviest in remote areas. However, the high cost of delivering dialysis services in remote areas has resulted in centralisation, requiring many people to relocate for treatment. Patients argue that treatment closer to home improves health outcomes and reduces downstream healthcare use. Existing dialysis cost studies have not compared total health care costs associated with treatment in different locations.

Objective: To estimate and compare, from a payer perspective, the observed health service costs (all cause hospital admissions, emergency department presentations and maintenance dialysis) associated with different dialysis models in urban, rural and remote locations.

Methods: Using cost weights attributed to diagnostic codes in the NT Department of Health's hospital admission data set (2008-2014), we calculated the mean (SD) total annual health service costs by dialysis model for 995 dialysis patients. Generalized linear modeling with bootstrapping tested the marginal cost differences between different explanatory variables to estimate 'best casemix'/'worst casemix' cost scenarios.
\end{abstract}

Results: The mean annual patient hospital expenditure was highest for urban models at \$97 928 (SD \$21 261) and \$43 440 (SD \$5 048) and lowest for remote at \$19 584 (SD \$4 394). When combined with the observed maintenance dialysis costs, expenditure was the highest for urban models at \$148 510 (SD \$19 774). The incremental cost increase of dialysing in an urban area, compared with a rural area, for a relocated person from a remote area, was $\$ 5648$ more and increased further for those from remote and very remote areas to $\$ 10785$ and $\$ 15118$ respectively.

Conclusions: This study demonstrates that dialysis treatment in urban areas for relocated people has health and cost implications that maybe greater than the cost of remote service delivery. The study emphasises the importance of considering all health service costs and cost consequences of service delivery models.

\footnotetext{
* Correspondence: gillian.gorham@menzies.edu.au

${ }^{1}$ Menzies School of Health Research, Charles Darwin University, PO Box

41096, Casuarina, 0810 Darwin, Australia

Full list of author information is available at the end of the article
}

\section{$\triangle B M C$}

(c) The Author(s). 2021 Open Access This article is licensed under a Creative Commons Attribution 4.0 International License, which permits use, sharing, adaptation, distribution and reproduction in any medium or format, as long as you give appropriate credit to the original author(s) and the source, provide a link to the Creative Commons licence, and indicate if changes were made. The images or other third party material in this article are included in the article's Creative Commons licence, unless indicated otherwise in a credit line to the material. If material is not included in the article's Creative Commons licence and your intended use is not permitted by statutory regulation or exceeds the permitted use, you will need to obtain permission directly from the copyright holder. To view a copy of this licence, visit http://creativecommons.org/licenses/by/4.0/ The Creative Commons Public Domain Dedication waiver (http://creativecommons.org/publicdomain/zero/1.0/) applies to the data made available in this article, unless otherwise stated in a credit line to the data. 
Key points for decision makers: Relocation for dialysis treatment has serious health and economic consequences. Relocated people have low dialysis attendance and high hospital costs in urban areas. While remote dialysis service models are more expensive than urban models, the comparative cost differences are significantly reduced when all health service costs are included. The delivery of equitable and accessible dialysis service models requires a holistic approach that incorporates the needs of the patient; hence dialysis cost studies must consider the full range of cost impacts beyond the dialysis treatments alone.

\section{Plain language summary}

Most people requiring ongoing treatment for end-stage kidney disease in the Northern Territory (NT) identify as Aboriginal with the majority residing in areas classified as remote or very remote. Unlike other jurisdictions in Australia, haemodialysis in a satellite unit is the most common form of treatment. However, there is a geographic mismatch between demand and service provision, with services centralised in urban areas. Patients and communities have long advocated for services at or closer to home, maintaining that the consequences of relocation and dislocation have far reaching health, psychosocial and economic ramifications. We analysed retrospective hospital data for 995

maintenance dialysis patients, stratified by the model of care they received in urban, rural and remote locations. Using cost weights attributed to diagnosis codes, we costed hospital admissions, emergency department presentations and maintenance dialysis attendances, to provide a mean total health service cost/patient/year for each model of care. We found that urban services were associated with low observed maintenance dialysis and high hospital costs, but the inverse was true for remote and very remote models. Remote models had high maintenance dialysis costs (due to expense of remote service delivery and good dialysis attendance) but low hospital usage and costs. When adjusted for other variables such as age, dialysis vintage and comorbidities, lower total hospital costs were associated with rural and remote service provision. In an environment of escalating demand and constrained budgets, this study underlines the need for policy decisions to consider the full cost consequences of different dialysis service models.

\section{Background}

Treatment for end stage kidney disease (ESKD) places an enormous burden on the health system globally and is estimated to cost one billion dollars (AUD) annually in Australia [1]. The treatment for ESKD includes transplantation, haemodialysis (facility-based and home), and peritoneal dialysis, collectively described as renal replacement therapy (RRT). The comparable costs of RRT have been regularly estimated globally, nationally and by jurisdictions, as governments and service providers strive to provide high-cost therapies within increasingly constrained health budgets [2-7].

Self-care therapies of home haemodialysis (HHD) and peritoneal dialysis (PD) are estimated to be the least costly although cost studies vary on the comparative cost differences between HHD and PD. Estimates differ by country, jurisdiction and even locations within States and Territories [8-11]. Self-care therapies are not suited to all individuals and often have a limited treatment life. In Australia most individuals requiring RRT receive haemodialysis in a staffed "satellite" facility, recognised as the most expensive RRT option [12].

Studies have suggested a relationship between the frequency and cost of hospitalisations and specific treatment modalities [13-16]. A few cost studies have also compared the delivery of dialysis treatments across different locations, noting the increased infrastructure and recurrent costs per patient per year associated with remote based services [17-19].

The prevalence of ESKD in Australia is highest in the Northern Territory (NT), with Aboriginal Territorians requiring $R R T$ at more than 10 times the national rate [20]. The burden of kidney disease in the NT is heaviest in remote areas where most Aboriginal Territorians live [21], yet renal and dialysis services are largely centralised in the two urban areas. As a result, most Aboriginal people relocate for treatment, often permanently.

Dialysis service development in rural and remote locations have been limited by concerns regarding the comparatively high establishment and recurrent costs of staffed facilities and the limited capacity of remote primary health services to care for complex conditions, such as ESKD [22-24].

However medical relocation inevitably involves lifechanging economic and psychosocial costs, including decreased uptake of RRT [25-27]. While there are strong arguments that improving service accessibility would both improve outcomes and decreases costs [28-30], a rigorous assessment of total health service costs has not been completed to date.

\section{Objective}

The objective of this study was to examine the total health system costs associated with the delivery of 
dialysis models of care in urban, rural and remote locations from the payer perspective. Health system costs included all cause hospital admissions, emergency department (ED) presentations and maintenance dialysis costs.

Our aim was to estimate and compare the observed mean total costs/patient/year by dialysis model of care and model different casemix scenarios to identify patient characteristics that predicted significant changes in hospital costs.

\section{Methods}

\section{Overall study design}

Australia's health system is described as a hybrid model. It consists of publicly funded health services based on the premise of universal access to health care, and privately funded services based on user choice [31]. Renal services in the NT are wholly publicly funded as the single private hospital does not provide dialysis treatments. This study took the payer perspective and only included direct health care costs. Patient out of pocket costs, including costs associated with medical relocation were excluded. Costs are reported in 2017 Australian dollars.

We conducted a retrospective analysis of total health service expenditure (dialysis treatments, hospital admissions and ED presentations) for renal patients in the NT between the years 2008-2014. Total health service expenditure was calculated using two approaches:

1) Observed all cause hospital admissions costs, based on the Australian Refined Diagnosis-Related Groups (AR-DRG), a classification system used in Australia for grouping diagnoses/conditions requiring similar hospital services to calculate public hospital funding on an activity basis. Average cost weights are attributed to each episode of care [32]; and.

2) published data of per dialysis treatment costs (inclusive of infrastructure costs) from a recent micro-costing analysis of dialysis program expenditure in the NT [19].

\section{Setting}

The NT, based in northern Australia, is a large land mass with a relatively small, sparsely dispersed population. The majority of the NT is classified as remote or very remote according to the Australian Statistical Geography Standard-Remoteness Area (ASGS-RA) classification, which divides Australia into five classes of remoteness based on access to services [33].

Most people live in the two main urban centres of Darwin and Alice Springs, but the majority (70\%) of Aboriginal people, who make up $30 \%$ of the NT population, live in remote/very remote communities [34]. More than $85 \%$ of people receiving RRT in the NT identify as
Aboriginal. At the time of this study, most staffed dialysis services were centralised in the urban areas of Darwin and Alice Springs with only limited dialysis services available in remote locations. These small services were usually at capacity with waiting lists. Consequently, $75 \%$ of people receiving care in the urban areas, had moved from very remote areas, often crossing state boundaries to access treatment.

\section{Dialysis Models of Care}

The cohort for this study was established as part of the broader DxMoC [35] project where we conducted a retrospective analysis using deidentified linked clinical and administrative data sets to examine health service utilisation in the NT between 2008 and 2014 (under review). Details of the analysis are available in the electronic supplementary material (ESM). The deidentified data sets were used in this study and all data analysis was performed in accordance with the relevant guidelines and regulations of the relevant ethics committees and in accordance with the Declaration of Helsinki.

We stratified admissions for each patient receiving dialysis in the NT between 2008 and 2014 according to the type and location of dialysis treatment, characterized as a Dialysis Model of Care (DxMoC). We did not include kidney transplantation in the study (see Table 1).

\section{Study cohort}

The study population was derived from the NT Department of Health's Admitted Patient Care (hospital) data set and based on the presence of diagnosis or procedure codes for RRT (International Classification of Diseases Version 10 Australian Modification (ICD 10AM)). The hospital data set contained individual episodes of patient care for the five parent hospitals and satellite dialysis services in the NT. Besides an individual's demographic details (age, ethnicity, residence), episode data also included the AR-DRG for each admission including maintenance dialysis.

The hospital data set was linked with activity data from: (a) interstate patient travel information $(\mathrm{n}=171)$; and (b) dialysis data from individuals who received care in DxMoC4 and DxMoC5 $(\mathrm{n}=189)$ not captured in the hospital data set. The collection of maintenance dialysis data for DxMoC4 and DxMoC5 was known to be inconsistent, and manual compilation of activity and linkage with the hospital data set was undertaken by an independent linker. Costs were attributed according to the representative AR-DRG.

The study population comprised of 995 maintenance dialysis patients, defined as individuals who received dialysis for more than three months continuously (Fig. 1). The analysis was restricted to 2008 to 2014 to ensure sufficient 
Table 1 Dialysis services in the NT characterised as Dialysis Models of Care

\begin{tabular}{|c|c|c|}
\hline $\begin{array}{l}\text { Dialysis } \\
\text { Model }\end{array}$ & Description & Characteristics \\
\hline $\begin{array}{l}\text { DxMoCo } \\
\text { Incentre } \\
\text { dialysis }\end{array}$ & $\begin{array}{l}\text { Hub service: situated in tertiary centre: acute and maintenance } \\
\text { haemodialysis }\end{array}$ & $\begin{array}{l}\text { Majority of patients commence treatment here: used for } \\
\text { complex patients and overflow from satellite centres }\end{array}$ \\
\hline $\begin{array}{l}\text { DxMoC1 } \\
\text { Urban } \\
\text { Satellite Unit }\end{array}$ & Large facilities in urban areas: maintenance haemodialysis & $\begin{array}{l}\text { All patients stabilised here: default service when rural and } \\
\text { remote services at capacity }\end{array}$ \\
\hline $\begin{array}{l}\text { DxMoC2 } \\
\text { Rural Satellite } \\
\text { Unit }\end{array}$ & $\begin{array}{l}\text { Smaller facilities: often co-located with regional hospitals: mainten- } \\
\text { ance haemodialysis }\end{array}$ & Usually for stable patients: generally a waiting list \\
\hline $\begin{array}{l}\text { DxMoC3 } \\
\text { Remote } \\
\text { Satellite Unit }\end{array}$ & $\begin{array}{l}\text { Small units isolated from hub by distance or geography: maintenance } \\
\text { haemodialysis }\end{array}$ & $\begin{array}{l}\text { Generally reserved for clinically well, physically mobile } \\
\text { patients: generally a waiting list }\end{array}$ \\
\hline $\begin{array}{l}\text { DxMoC4 } \\
\text { Remote CC } \\
\text { Satellite Unit }\end{array}$ & $\begin{array}{l}\text { Aboriginal owned and determined; small remote based units } \\
\text { providing permanent and respite dialysis with social supports. }\end{array}$ & $\begin{array}{l}\text { Patient acceptance criteria less restrictive as more suppor } \\
\text { services available: generally a waiting list }\end{array}$ \\
\hline $\begin{array}{l}D \times M O C 5 \\
S C H D^{b}\end{array}$ & Training and support for independent haemodialysis & $\begin{array}{l}\text { Clinically stable, deemed capable and safe to deliver own } \\
\text { care }\end{array}$ \\
\hline $\begin{array}{l}\text { DXMoC6 } \\
\text { SCPDC }\end{array}$ & Training and support for independent peritoneal dialysis & $\begin{array}{l}\text { Clinically stable, deemed capable and safe to deliver own } \\
\text { care }\end{array}$ \\
\hline
\end{tabular}

${ }^{\mathrm{a} C C}$ Community controlled, ${ }^{\mathrm{b} S C} H D$ Self care haemodialysis, ${ }^{\mathrm{C}} S C$ PD Self care peritoneal dialysis

activity was available across all models (new and developing) and to marry with the micro-costing analysis time frame [19]. Eight patients $(n=8)$ were excluded as they did not have any cost data (Fig. 1). Data was censored at death or withdrawal (based on coding) or loss to followup (LTFU) defined as no entry in the data for 12 months or more, without re-entry. Patients who had missing data for 12 months or more (transplanted, moved interstate) but re-appeared in the data set were characterized as intermittent LTFU (iLTFU) for that period.

\section{Data management}

The data was checked and cleaned to ensure consistency of demographic variables (such as gender and ethnicity) and duplicate attendances removed. Same day attendance at both a dialysis facility and the ED, which did not result in an overnight admission $(n=3716)$ were retained as these records represent additional quantifiable resource allocations.

Variables for the presence of select comorbidities prevalent in ESKD and considered to have a significant impact on health outcomes were created (diabetes, cardiac disease, vascular disease, hypertension, cerebrovascular disease and obesity) based on the presence of relevant ICD 10AM codes. These were carried forward to subsequent episodes once present. Other variables that were considered relevant included region (Top End and Central Australia), time on dialysis, age at admission, Aboriginal status and remoteness of residence prior to commencement of RRT start.

In the NT, there is significant movement between DxMoC with variability across models in the number and proportion of patients that spend a full year in any DxMoC (Table 2). When mapped, DxMoC0 had the lowest proportion of patients $(3 \%)$ with a full year, with a median time in model of 0.33 year (IQR: 0.13-0.67). This was not unexpected given the model is primarily reserved for new patients and complex care. Similarly, DxMoC4, primarily a respite model, only had $9 \%$ of patients with a full year and a median time in model of 0.76 year (IQR:0.36-0.94).

Due to this mobility, the attribution of hospital costs to a specific DxMoC required careful analysis and testing of approaches. The dominant dialysis model of care for each patient was based on rolling attendance over three weeks. This was designed to reduce the "noise" of frequent movement between models while still enabling the respite model (DxMoC4) of 2 to 3 weeks to be captured in the data.

\section{Person years}

Time (weeks) spent in a DxMoC per year was calculated as the exposure time specific to a model of care and was used in the calculation of person years. Exposure time was censored at death or permanent loss to follow-up. Person years was calculated for each DxMoC and for each year of the study. The full list of variables (definitions and calculations) can be found in the ESM.

\section{Cost data management}

Costs were attributed to each admission according to the AR-DRG. Seven (7) admissions were uncoded, with neither AR-DRG or ICD 10AM codes present. These 


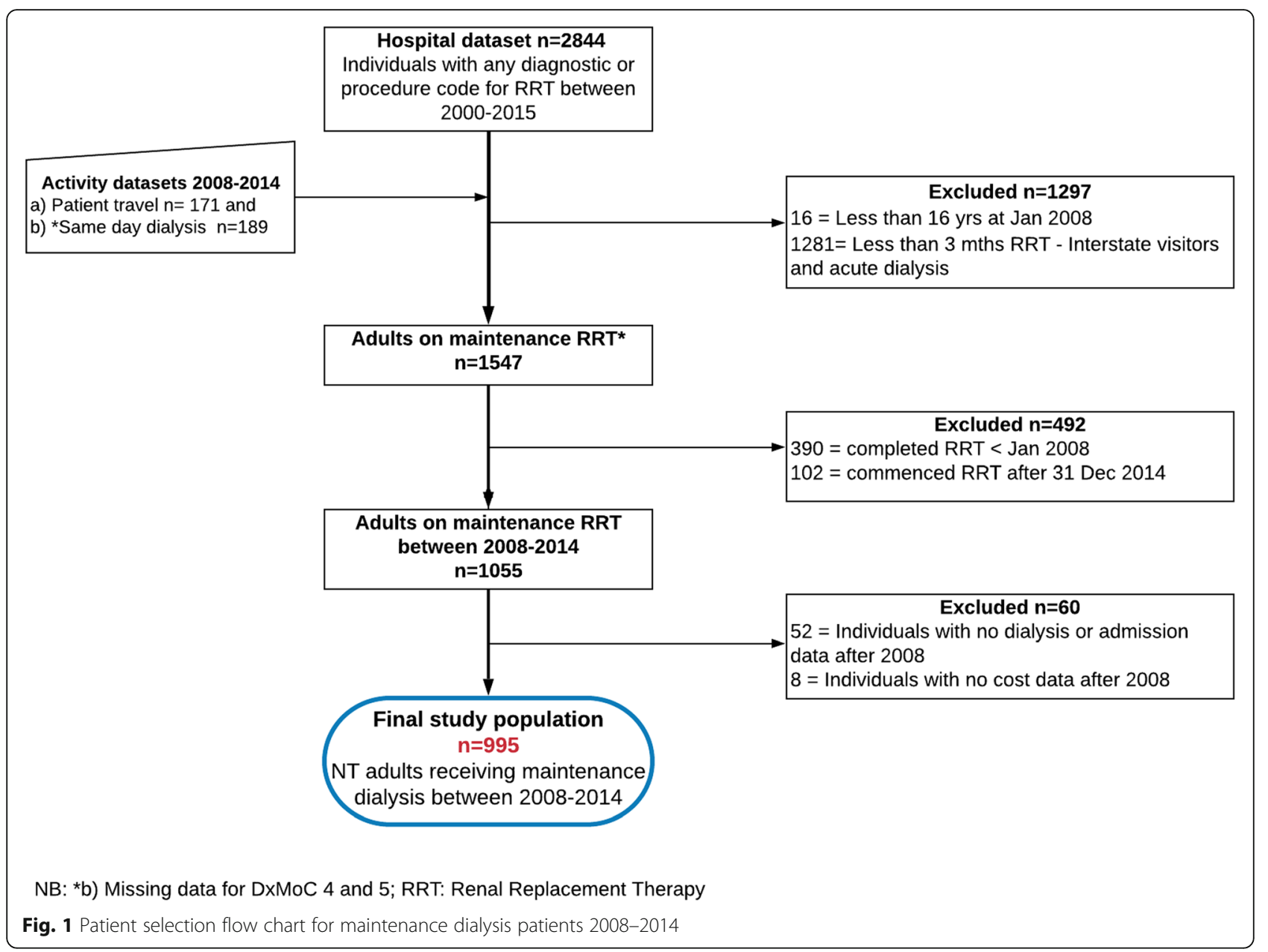

were allocated a generic AR-DRG based on the length of hospital admission.

Dummy cost variables were created to identify and differentiate the dialysis costs between the different DxMoC not represented in the hospital data set. For instance, while maintenance dialysis as an outpatient is captured for each treatment as a same day admission, the cost differential between different models and regions are not adequately recognised in the case mix funding model. The cost for each same day dialysis at each DxMoC was replaced with the relevant and representative cost from the micro costing study [19]. Incentre haemodialysis (DxMoC0) is accepted as being more expensive than satellite dialysis (DxMoC1) [36, 37]. As DxMoC0 was not included in the micro-costing study, we allocated the DxMoC1 cost value from the study inflated by $17 \%$, based on the incremental cost differences between DxMoC1 and DxMoC0 from the available research $[1,8,36-40]$.

Table 2 Patients experiencing full year in DxMoC 2008-2014 with mean (95\% Cl) and median (IQR) time

\begin{tabular}{llcr}
\hline DxMoC and patients $(\mathbf{n})$ & Full year $\mathbf{n}(\%)$ & Mean time $(\mathbf{9 5} \% \mathbf{C l})$ & Median time (IQR) \\
\hline DXMoC0 $(n=692)$ & $18(3 \%)$ & $0.43(0.42-0.43)$ & $0.33(0.13-0.67)$ \\
DXMoC1 $(n=865)$ & $473(55 \%)$ & $0.88(0.88-0.88)$ & $1(0.86-1)$ \\
DXMoC2 $(n=199)$ & $102(51 \%)$ & $0.90(0.90-0.90)$ & $1(0.94-1)$ \\
DXMoC3 $(n=41)$ & $24(59 \%)$ & $0.89(0.88-0.89)$ & $1(0.88-1)$ \\
DXMoC4 $(n=131)$ & $12(9 \%)$ & $0.66(0.65-0.66)$ & $0.76(0.36-0.94)$ \\
DXMoC5 $(n=128)$ & $49(38 \%)$ & $0.87(0.86-0.87)$ & $1(0.81-1)$ \\
DXMoC6 $(n=158)$ & $86(54 \%)$ & $0.85(0.85-0.86)$ & $1(0.81-1)$ \\
\hline
\end{tabular}


Costs for self-care training for both DxMoC5 (Selfcare HD) and DxMoC6 (Self-care PD) were only applied to incident patients (those starting RRT after January 2008), and only in the first year of allocation to the model. The training cost for DxMoC5 was based on findings from the micro-cost study which included a lengthy training period of up to six months. Yearly DxMoC6 costs were applied as a proportion of the time spent in the model. The replacement costs for AR-DRG code L61Z (same day haemodialysis) and one-off costs applied for DxMoC6 (peritoneal dialysis) based on the representative values from the micro costing study [19] are in Table 3.

\section{Statistical analysis}

All analyses were conducted using Stata15.1@ (StataCorp., College Station; Texas USA). Descriptive statistics included the total mean and standard deviation for all health service costs (overnight admissions, ED presentations and maintenance dialysis costs) and health service costs per person year.

We considered and tested a range of models for goodness of fit including a two part generalized linear model (GLM) [41]. We explored the completeness of costs for each individual and by DxMoC to determine the level of 'missingness' and if cost imputation was required [42]. We used a standard GLM (as the inclusion of zero costs was important in this context) to test marginal effects and a modified Park Test to determine the link family [43]. The GLM with log and gamma family (and a cluster option to account for multiple observations) was then used to test the marginal cost differences between different explanatory variables to create models to predict 'best casemix'/'worst casemix' cost scenarios [44]. Bootstrapping of 2000 repetitions was used to test the robustness of cost outputs and to account for the unevenness of utilisation between DxMoC.

\section{Results}

Study population

Of the nine hundred and ninety-five individuals who met the inclusion criteria, there were more females than males, with Aboriginal people making up the majority of the study cohort (90\%). There was homogeneity across age at study entry and median study time with little variance by gender and Aboriginal status.

Overall, $75 \%$ of the study population had a residential address outside of the urban areas of Darwin and Alice Springs (greater than $90 \mathrm{~min}$ drive) prior to the start of RRT. The proportion of people with a recorded

Table 3 Replacement unit costs for same day haemodialysis and peritoneal dialysis activity, \$2017

\begin{tabular}{|c|c|c|}
\hline $\begin{array}{l}\text { Model of care and } \\
\text { region* }\end{array}$ & $\begin{array}{l}\text { Replacement unit cost for AR-DRG } \\
\text { L61Z [13] }\end{array}$ & Applied \\
\hline DXMoCO - TE & $\$ 682.41$ & All patients in model \\
\hline DxMoCO $-C^{1 a}$ & $\$ 662.59$ & All patients in model \\
\hline DXMoC1 - TE & $\$ 583.26$ & All patients in model \\
\hline DXMoC1 - CA & $\$ 566.32$ & All patients in model \\
\hline DXMoC2 - TE & $\$ 519.29$ & All patients in model \\
\hline DxMoC2 - CA & $\$ 565.70$ & All patients in model \\
\hline DXMoC3 - TE & $\$ 798.03$ & All patients in model \\
\hline DxMoC4 - CA & $\$ 770.33$ & All patients in model \\
\hline DxMoC5 - TE (training) & $\$ 579.17$ & Incident patients to DxMoC5 - applied to first 180 days in model \\
\hline $\begin{array}{l}\text { DxMoC5 - TE post } \\
\text { training }\end{array}$ & $\$ 275.17$ & Prevalent patients and after first 180 days in model for incident patients \\
\hline $\begin{array}{l}\text { DxMoC5 - CA } \\
\text { (training) }\end{array}$ & $\$ 850.85$ & Incident patients to DxMoC5 - applied to first 180 days in model \\
\hline $\begin{array}{l}\text { DxMoC5 - CA post } \\
\text { training }\end{array}$ & $\$ 435.90$ & Prevalent patients and after first 180 days in model for incident patients \\
\hline DxMoC6 - TE (training) & $\$ 33,260.00$ & Incident patients to DxMoC6 - one off amount in first year DxMoC6 appears \\
\hline $\begin{array}{l}\text { DxMoC6 - TE post } \\
\text { training }\end{array}$ & $\$ 58,489.18$ & $\begin{array}{l}\text { Prevalent patients with annual cost proportioned to time in DxMoC6 (exclusive of } 6 \\
\text { weeks training time) }\end{array}$ \\
\hline $\begin{array}{l}\text { DxMoC6 - CA } \\
\text { (training) }\end{array}$ & $\$ 17,854.00$ & Incident patients to DxMoC6 - one off amount in first year DxMoC6 appears \\
\hline $\begin{array}{l}\text { DxMoC6 - CA post } \\
\text { training }\end{array}$ & $\$ 61,427.59$ & $\begin{array}{l}\text { Prevalent patients with annual cost proportioned to time in DxMoC6 (exclusive of } 6 \\
\text { weeks training time) }\end{array}$ \\
\hline
\end{tabular}

*Region: TE: Top End, CA: Central Australia; ${ }^{1 a}$ Based on DxMoC1 costs inflated by 17\% - using average incremental cost difference between DxMoC1 (urban services) and DxMoC0 (incentre facility) from seven studies [28-31] 
comorbidity of diabetes and cardiac disease was more common in Aboriginal people than non-Aboriginal people (Table 4).

\section{Health service utilisation}

Health service costs were separated by overnight hospital admissions, ED presentations not resulting in an overnight admission and maintenance dialysis (same day haemodialysis and annual (pro rata) peritoneal dialysis expenditure). Overnight admission and ED costs are referred to collectively as 'hospital service' costs.

Expenditure was examined for each patient, each year and by $\mathrm{DxMoC}$. While our analysis used methodology that allowed prediction of costs, our primary objective was to determine the relative overall observed costs for each DxMoC. Approximately $80 \%$ of patients incurred at least one overnight admission each year and $35 \%$ presented to the ED at least once in a year. Approximately $15 \%$ of patients each year had neither a hospital admission nor ED presentation and therefore had zero health service costs other than maintenance dialysis costs. Health service activity for patients in each year is presented in Table 5.

The completeness of activity for each patient was examined to determine reasons for partial activity. Approximately $70 \%$ of patients each year had a full year of activity. Partial year costs were due to a variety of reasons including incidence, death and loss to follow-up (LTFU). Patients who did not have a full year of activity in 2014 but were expected to (that is, were not transplanted, deceased or on DxMoC6) were characterized as LTFU. This is likely to have inflated the counts for LTFU in 2014 as it is not possible to know whether the individuals reappeared in the data set in 2015 (Table 6).
We determined that partial year costs were not due to missing data (missing at random (MAR)) [42] and the analysis by person years would account for incomplete years when determining the mean costs. We did not impute missing costs.

\section{Health Service Costs}

Hospital service costs were positively skewed. The crude mean annual hospital service expenditures stratified by DxMoC, are presented in Table 7. All costs are in \$2017 Australian dollars.

Mean annual hospital patient costs (calculated by dividing total hospital service costs by person years) for each DxMoC were highest for DxMoC0, with a mean cost of \$97 928 (SD: \$21 261) and lowest for DxMoC3 with a mean cost of \$19 584 (SD: \$4 394). When combined with the observed maintenance dialysis costs, expenditure was the highest for DxMoC0 at \$148 514 (SD $\$ 19$ 774) followed by DxMoC3/4 at $\$ 132280$ and $\$ 130$ 846, respectively (Fig. 2 a). Where the annual dialysis patient costs from the micro-costing study [19] were used instead of the observed maintenance dialysis costs, total costs were generally consistent (within 10-15\%) for all DxMoC except DxMoC0 and DxMoC1 (Fig. 2 b). The observed annual dialysis expenditure per patient was lower by 50 and $20 \%$ for DxMoC0 and DxMoC1 respectively (Fig. 2 a), compared to the micro-costing analysis (Fig. 2 b), due to the lower observed attendances in these DxMoC.

\section{Case mix factors in health service costs}

Using GLM regression we predicted low cost and high cost casemix scenarios based on the marginal and incremental costs attributed to different exposure variables.

Table 4 Patient characteristics by first episode in data set by gender and Aboriginal status

\begin{tabular}{|c|c|c|c|c|c|}
\hline \multirow{2}{*}{$\begin{array}{l}\text { Characteristics of cost study } \\
\text { cohort }\end{array}$} & \multirow[t]{2}{*}{$n=995$} & \multicolumn{2}{|c|}{ Aboriginal $n=892(90 \%)$} & \multicolumn{2}{|c|}{ Non-Aboriginal $n=103(10 \%)$} \\
\hline & & Female & Male & Female & Male \\
\hline Gender (female) n (\%) & $566(57 \%)$ & $526(59 \%)$ & $366(41 \%)$ & $40(39 \%)$ & $63(61 \%)$ \\
\hline Mean age at study entry (SD) & $51(11.7)$ & $51(11.4)$ & $50(11.0)$ & $50(16.0)$ & $56(14.7)$ \\
\hline Median study time (IQR) & $3.2(1.5-5.7)$ & $3.3(1.4-5.8)$ & $3.2(1.5-5.6)$ & $3.2(1.6-5.7)$ & $3.1(1.3-4.9)$ \\
\hline \multicolumn{6}{|l|}{ Relocation } \\
\hline Relocated n (\%) & $743(75 \%)$ & $429(82 \%)$ & $304(83 \%)$ & $4(10 \%)$ & $6(10 \%)$ \\
\hline Residence pre RRT (very remote) & $703(71 \%)$ & $407(77 \%)$ & $288(78 \%)$ & $3(7 \%)$ & $5(8 \%)$ \\
\hline \multicolumn{6}{|l|}{ Comorbidities at study entry } \\
\hline Diabetes & 767 (77\%) & $439(84 \%)$ & $287(79 \%)$ & $20(49 \%)$ & $21(33 \%)$ \\
\hline Cardiac Disease & $480(48 \%)$ & $256(49 \%)$ & $188(51 \%)$ & $15(37 \%)$ & $21(33 \%)$ \\
\hline Vascular Disease & $333(33 \%)$ & $183(35 \%)$ & $118(32 \%)$ & $9(22 \%)$ & $23(37 \%)$ \\
\hline Obesity & $116(12 \%)$ & $58(11 \%)$ & $50(14 \%)$ & $4(10 \%)$ & $4(6 \%)$ \\
\hline Hypertension & 910 (91\%) & 487 (93\%) & 339 (93\%) & 34 (85\%) & $50(79 \%)$ \\
\hline Cerebrovascular Disease & $49(5 \%)$ & $24(5 \%)$ & $25(7 \%)$ & $0(0 \%)$ & $5(8 \%)$ \\
\hline
\end{tabular}


Table 5 Health service activity for patients active in each year excluding same day dialysis

\begin{tabular}{|c|c|c|c|c|c|c|c|}
\hline Health service use & $\begin{array}{l}2008(n= \\
474)\end{array}$ & $\begin{array}{l}2009(n= \\
483)\end{array}$ & $\begin{array}{l}2010(n= \\
511)\end{array}$ & $\begin{array}{l}2011(n= \\
548)\end{array}$ & $\begin{array}{l}2012(n= \\
587)\end{array}$ & $\begin{array}{l}2013(n= \\
621)\end{array}$ & $\begin{array}{l}2014(n= \\
647)\end{array}$ \\
\hline Admitted patients n (\%) & $378(80 \%)$ & $380(79 \%)$ & $411(80 \%)$ & $440(80 \%)$ & $467(80 \%)$ & $502(81 \%)$ & $528(82 \%)$ \\
\hline Overnight admission episodes $=n$ & 1325 & 1485 & 1724 & 1725 & 1756 & 2009 & 2376 \\
\hline Patients presenting to $\mathrm{ED}^{\mathrm{a}} \mathrm{n}(\%)$ & $164(35 \%)$ & $178(37 \%)$ & 169 (33\%) & $182(33 \%)$ & $196(33 \%)$ & $226(36 \%)$ & $247(38 \%)$ \\
\hline ED presentation episodes $=n$ & 377 & 449 & 487 & 492 & 515 & 689 & 727 \\
\hline $\begin{array}{l}\text { Zero hospital and ED presentations } n \\
(\%)\end{array}$ & $72(15 \%)$ & $71(15 \%)$ & $74(14 \%)$ & $84(15 \%)$ & $81(14 \%)$ & $88(14 \%)$ & $79(12 \%)$ \\
\hline
\end{tabular}

${ }^{a}$ Emergency Department

As DxMoC1 had the largest patient population and activity, this model was used as the comparative reference for all other DxMoC. Region, dialysis vintage, comorbidities of diabetes, cardiac disease and vascular disease and DxMoC were significant in the modelling $(\mathrm{P}<0.001)$. Results are presented for Aboriginal people as they made up the majority of the cohort ( $90 \%)$, and all attendances at $\mathrm{DxMoC2}-4$.

We predicted the costliest casemix would include male gender, relocated from a very remote border community for dialysis treatment, dialysis vintage of less than 12 months, age between 30 and 39 years, with a comorbid condition of vascular disease and receiving care within the Central Australian (CA) region at DxMoC0 or DxMoC1. This casemix incurred between $\$ 88635$ and $\$ 91935$ in hospitalisation costs each year.

In contrast, the low cost casemix scenario included demographic factors such as an older (between 50 and 59 years of age) female, from the urban area, on dialysis for 4-5 years, dialysing in the Top End (TE) region at DxMoC5 (self-care HD). Hospital costs were predicted to be significantly lower (\$22 434), and this remained the case even if a major comorbidity such as vascular disease, was included (\$33 158).

We used 50-59 years as the age reference group as this was close to the mean age of the study cohort (Table 4). For each model, we noted costs decreased with each older age group and with each dialysis vintage grouping (Table 8).
High cost casemix scenarios included remote residence pre RRT, being new to dialysis (less than 12 months), relatively young (30-39 years), with a comorbidity such as vascular disease and dialysing in the urban area $(\mathrm{DxMoC0} / 1)$ in CA. Other than presence of a select comorbidity, this combination of factors is common in Northern Territory dialysis patients. This casemix predicted hospital costs between $\$ 100$ 079 and \$104 777 annually.

The lowest cost casemix could be attributed to a combination of characteristics that included an older (50-59 years) female, with no comorbidities who had been on dialysis for 4-5years and either originally from the urban area and undertaking DxMoC5 OR originally from the remote area and dialysing in DxMoC4.

At the very least, the incremental cost for an Aboriginal person dialysing in a rural $(\mathrm{DxMoC} 2)$ area was $\$ 5$ 694 lower, compared with a relocated Aboriginal person (with all other things being equal) dialysing in the urban area (DxMoC1). The incremental cost reduction compared to urban dialysis was dependent on remoteness, with DxMoC3 having, on average, $\$ 10818$ lower costs than DxMoC1, and DxMoC4 having \$15 125 lower costs than DxMoC1 (Table 8).

\section{Discharge diagnosis for DxMoC}

We examined the type and frequency of admissions (based on AR-DRG discharge codes) to better understand what other factors impact on DxMoC hospital costs. There was variation in the most frequent

Table 6 Number and proportion of patients with complete and partial year costs by year

\begin{tabular}{|c|c|c|c|c|c|c|c|}
\hline $\begin{array}{l}\text { Year of study and patient } \\
\text { numbers }\end{array}$ & $\begin{array}{l}2008(n= \\
474)\end{array}$ & $\begin{array}{l}2009(n= \\
483)\end{array}$ & $\begin{array}{l}2010(n= \\
511)\end{array}$ & $\begin{array}{l}2011(n= \\
548)\end{array}$ & $\begin{array}{l}2012(n= \\
587)\end{array}$ & $\begin{array}{l}2013(n= \\
621)\end{array}$ & $\begin{array}{l}2014(n= \\
647)\end{array}$ \\
\hline $\begin{array}{l}\text { Patients with complete year costs } n \\
(\%)\end{array}$ & $327(69 \%)$ & $363(75 \%)$ & $388(76 \%)$ & $404(74 \%)$ & 431 (73\%) & $448(72 \%)$ & $439(68 \%)$ \\
\hline \multicolumn{8}{|l|}{ Part year costs due to } \\
\hline Incident & $80(17 \%)$ & $62(13 \%)$ & $64(12 \%)$ & 79 (14\%) & 89 (15\%) & $94(15 \%)$ & $92(14 \%)$ \\
\hline Death & $48(10 \%)$ & $34(7 \%)$ & $39(8 \%)$ & $37(7 \%)$ & $43(7 \%)$ & $42(7 \%)$ & $58(9 \%)$ \\
\hline Withdrew $^{d}$ & $5(1 \%)$ & $10(2 \%)$ & $5(1 \%)$ & $7(1 \%)$ & $2(0 \%)$ & $10(\% 1)$ & $9(1 \%)$ \\
\hline$\angle T F U^{b}$ & $1(0 \%)$ & $1(0 \%)$ & $0(0 \%)$ & $6(1 \%)$ & $5(1 \%)$ & $14(3 \%)$ & $43(7 \%)$ \\
\hline iLTFU ${ }^{a}$ including $T X^{c}$ & $13(3 \%)$ & $13(3 \%)$ & $15(3 \%)$ & $15(3 \%)$ & $17(4 \%)$ & $13(2 \%)$ & $6(1 \%)$ \\
\hline
\end{tabular}

${ }^{a}$ iLTFU Intermittent Loss to follow up, ${ }^{\mathrm{b}}$ LTFU Loss to follow up, ${ }^{\mathrm{c}} T x$ Transplantation, ${ }^{\mathrm{d}}$ Withdrew: palliated 
Table 7 Average annual health service expenditure by DxMoC and by patient years (2008-2014) \$AUS2017

\begin{tabular}{|c|c|c|c|c|c|c|c|}
\hline DxMoC costs & $\begin{array}{l}\text { Incentre } \\
\text { MoC0 }\end{array}$ & $\begin{array}{l}\text { Urban } \\
\text { DxMoC1 }\end{array}$ & Rural MoC2 & $\begin{array}{l}\text { Remote } \\
\text { MoC3 }\end{array}$ & $\begin{array}{l}\text { RemoteCC } \\
\text { MoC4 }\end{array}$ & SC HD MoC5 & SC PD MoC6 \\
\hline $\begin{array}{l}\text { Mean annual person years } \\
\text { (SD) }\end{array}$ & $26.9(3.5)$ & $293.2(33.9)$ & $65.5(9.9)$ & $15.2(3.3)$ & $20.2(9.9)$ & $33.5(7.7)$ & $42.6(8.2)$ \\
\hline Annual overnight costs (SD) & $\begin{array}{l}\$ 2384554 \\
(\$ 292382)\end{array}$ & $\begin{array}{l}\$ 10796590(\$ 2 \\
338105)\end{array}$ & $\begin{array}{l}\$ 2057456 \\
(\$ 536526)\end{array}$ & $\begin{array}{l}\$ 298030 \\
(\$ 110777)\end{array}$ & $\begin{array}{l}\$ 400455(\$ 198 \\
295)\end{array}$ & $\begin{array}{l}\$ 783561 \\
(\$ 262117)\end{array}$ & $\begin{array}{l}\$ 1195783 \\
(\$ 267061)\end{array}$ \\
\hline Annual ED cost (SD) & $\begin{array}{l}\$ 197395(\$ 69 \\
154)\end{array}$ & $\begin{array}{l}\$ 2080762 \\
(\$ 576588)\end{array}$ & $\begin{array}{l}\$ 161867(\$ 86 \\
244)\end{array}$ & $\begin{array}{l}\$ 5456(\$ 6 \\
402)\end{array}$ & $\begin{array}{l}\$ 104606(\$ 61 \\
532)\end{array}$ & $\begin{array}{l}\$ 37391(\$ 16 \\
678)\end{array}$ & $\begin{array}{l}\$ 67633(\$ 23 \\
333)\end{array}$ \\
\hline $\begin{array}{l}\text { Annual hospital (overnight } \\
\text { and ED) costs (SD) }\end{array}$ & $\begin{array}{l}\$ 2581949 \\
(\$ 339333)\end{array}$ & $\begin{array}{l}\$ 12887350(\$ 2 \\
897673)\end{array}$ & $\begin{array}{l}\$ 2219323 \\
(\$ 607166)\end{array}$ & $\begin{array}{l}\$ 303486 \\
(\$ 115358)\end{array}$ & $\begin{array}{l}\$ 505060(\$ 252 \\
482)\end{array}$ & $\begin{array}{l}\$ 820952 \\
(\$ 267606)\end{array}$ & $\begin{array}{l}\$ 1263416 \\
(\$ 276490)\end{array}$ \\
\hline Annual dialysis costs (SD) & $\begin{array}{l}\$ 1376173 \\
(\$ 267504)\end{array}$ & $\begin{array}{l}\$ 20648550(\$ 2 \\
412165)\end{array}$ & $\begin{array}{l}\$ 4787821 \\
(\$ 743545)\end{array}$ & $\begin{array}{l}\$ 1702762 \\
(\$ 322872)\end{array}$ & $\begin{array}{l}\$ 2140761(\$ 1 \\
048406)\end{array}$ & $\begin{array}{l}\$ 1496354 \\
(\$ 314784)\end{array}$ & $\begin{array}{l}\$ 2986276 \\
(\$ 554379)\end{array}$ \\
\hline $\begin{array}{l}\text { Total annual health service } \\
\text { costs (SD) }\end{array}$ & $\begin{array}{l}\$ 3958122 \\
\left(\begin{array}{l}\$ 391353)\end{array}\right.\end{array}$ & $\begin{array}{l}\$ 33525910(\$ 5 \\
185195)\end{array}$ & $\begin{array}{l}\$ 7007144(\$ 1 \\
244222)\end{array}$ & $\begin{array}{l}\$ 2006248 \\
(\$ 399797)\end{array}$ & $\begin{array}{l}\$ 2645821(\$ 1 \\
296984)\end{array}$ & $\begin{array}{l}\$ 2317(\$ 531 \\
984)\end{array}$ & $\begin{array}{l}\$ 4249692 \\
(\$ 673865)\end{array}$ \\
\hline $\begin{array}{l}{ }^{a} \text { Mean hospital costs/patient/ } \\
\text { yr (SD) }\end{array}$ & $\begin{array}{l}\$ 97928(\$ 21 \\
261)\end{array}$ & $\$ 43440(\$ 5048)$ & $\begin{array}{l}\$ 33630(\$ 7 \\
213)\end{array}$ & $\begin{array}{l}\$ 19584(\$ 4 \\
394)\end{array}$ & $\begin{array}{l}\$ 24914(\$ 4 \\
537)\end{array}$ & $\begin{array}{l}\$ 24432(\$ 6 \\
618)\end{array}$ & $\begin{array}{l}\$ 30699(\$ 8 \\
898)\end{array}$ \\
\hline $\begin{array}{l}{ }^{\mathrm{a}} \text { Mean dialysis costs/patient/ } \\
\text { yr (SD) }\end{array}$ & $\begin{array}{l}\$ 50582(\$ 4 \\
434)\end{array}$ & $\$ 70418(\$ 1169)$ & $\begin{array}{l}\$ 73118(\$ 1 \\
388)\end{array}$ & $\begin{array}{l}\$ 112696(\$ 6 \\
322)\end{array}$ & $\begin{array}{l}\$ 105932(\$ 3 \\
556)\end{array}$ & $\begin{array}{l}\$ 44959(\$ 4 \\
067)\end{array}$ & $\begin{array}{l}\$ 70391(\$ 4 \\
272)\end{array}$ \\
\hline $\begin{array}{l}{ }^{\text {a }} \text { Mean health service costs/ } \\
\text { patient/yr (SD) }\end{array}$ & $\begin{array}{l}\$ 148510(\$ 19 \\
774)\end{array}$ & $\begin{array}{l}\$ 113858(\$ 4 \\
891)\end{array}$ & $\begin{array}{l}\$ 106748(\$ 6 \\
364)\end{array}$ & $\$ 132280(\$ 3$ & $\begin{array}{l}\$ 130846(\$ 5 \\
280)\end{array}$ & $\begin{array}{l}\$ 69391(\$ 8 \\
169)\end{array}$ & $\begin{array}{l}\$ 101090(\$ 9 \\
421)\end{array}$ \\
\hline
\end{tabular}

${ }^{\mathrm{a} A n n u a l}$ costs divided by person years

discharge diagnosis between models. Kidney related conditions without complications was the most frequent hospitalisation AR-DRG for DxMoC0,1 and 4, while ARDRGs for DxMoC2 and 3 were respiratory related conditions with severe to moderate (but not catastrophic) complications. These conditions had cost weights twice as high as those for kidney related conditions (Table 9). However, discharge codes associated with DxMoC5 and 6 tended to be more acute (infections and obstructions) with severe or catastrophic complications and a cost weight three times that of the kidney related conditions. When the costs for the top three admission codes for each DxMoC were aggregated, the average per episode cost was considerably higher in DxMoC5 and 6 compared to all other models (Table 9).

\section{Discussion}

Maintenance dialysis is the most common form of RRT for Aboriginal people in the NT and throughout Australia. There is an abundance of literature on the cost of delivering different modalities; assessments have also been made on the broader health service cost consequences of each modality [45-47]. There is limited literature on the cost implications of dialysis delivery in different locations that also considers broader health service use.

Our findings support previous work that found annual maintenance dialysis costs were higher for rural and remote based DxMoC (DxMOC2-4) compared to urban based (DxMoC0/1) or self-care modalities (DxMoC5/6) [19]. However, this study also demonstrated that the costs associated with overnight admissions and ED presentations were much lower in these models. Based on observed individual attendances, the annual maintenance dialysis costs for DxMoC0 were lower than expected. Non-attendance for dialysis will result in lower maintenance dialysis costs, but as seen in this study, the downstream consequences include frequent admissions and higher overall health service costs. Frequent admissions and poor health also have an impact on quality of life and this in turn has cost consequences [48].

While the findings support our previous analysis (under review) that higher hospital presentations (and therefore costs) observed in DxMoC0 and DxMoC1 were less related to the characteristics of patients attending these models (such as age or comorbidities) than to dialysis attendance patterns, we acknowledge there are other reasons for hospitalisations. Most overnight episodes of care were for relatively uncomplicated, kidney related, short stays. However, the self-care therapies (DxMoC5/6) had lower observed admissions, but the discharge diagnoses and costs indicated these admissions were both more severe and complex, consistent with findings reported elsewhere $[49,50]$.

The casemix analysis examined patient characteristics that predict significant changes in hospital costs and found individual comorbidities and remoteness of residence pre RRT start contributed significant marginal costs. However, all else being equal, model of care was a significant contributing factor, with incremental costs for all DxMoC lower when compared to DxMoC0/1. The incremental cost difference was the largest for remote services (DxMoC3 and4) and the smallest (and non-significant) for DxMoC6. 


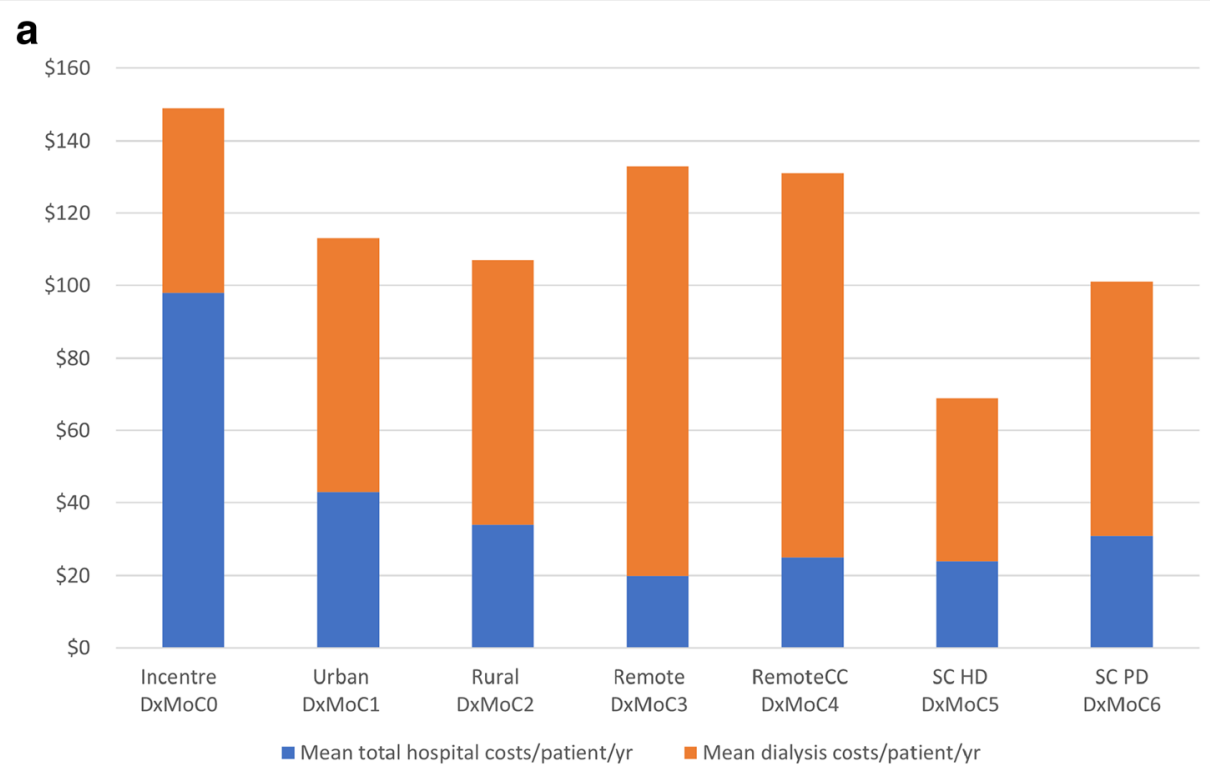

b

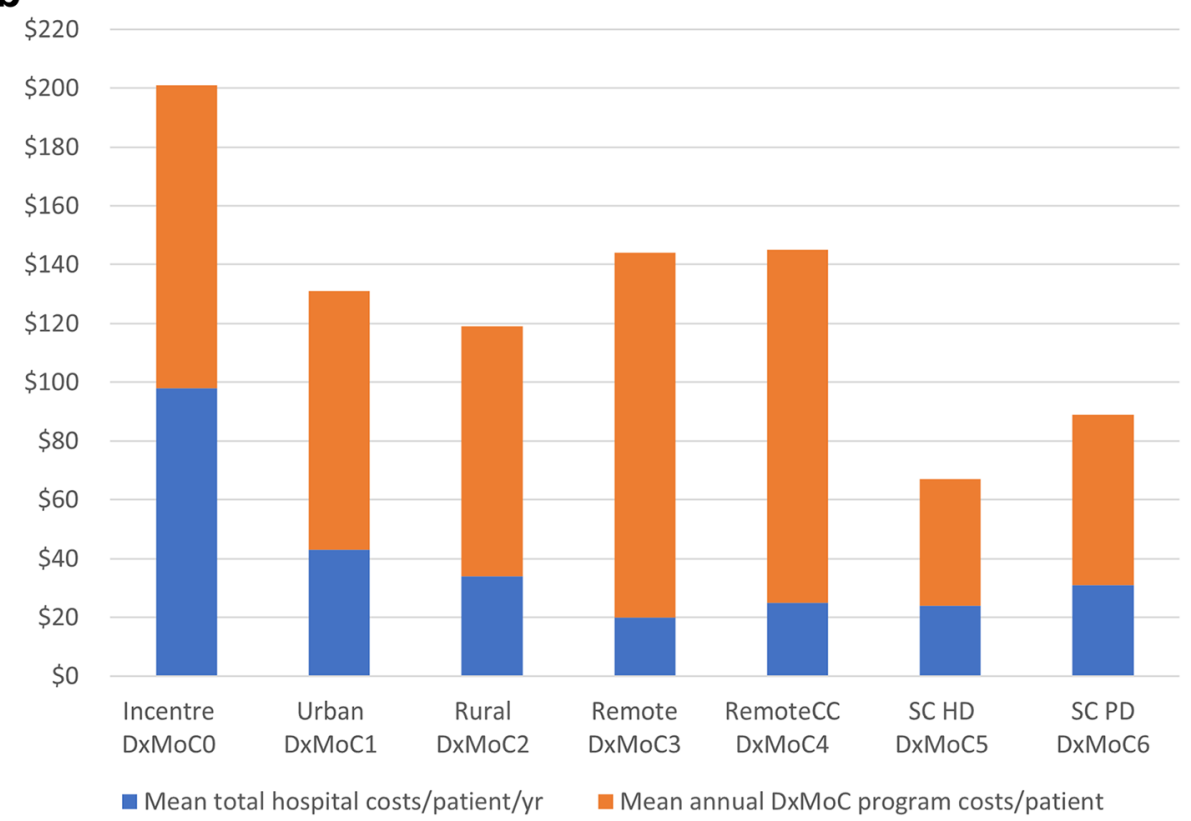

Fig. 2 a Observed mean annual hospital and maintenance dialysis costs/patient/year. b Observed mean annual hospital costs/patient/year with annual patient maintenance dialysis costs based on full annual attendance in a DxMoC from micro-costing analysis [19].

Our study was from the funder perspective and did not include the full impacts of relocation such as patient out of pocket (OOP) costs or psychosocial costs. OOP costs for relocated people are expected to be over and above the OOP costs experienced by dialysis patients in general. The impacts of relocation are substantial and often manifest in missed treatments and poorer health outcomes [51, 52]. However, these costs resonate well beyond the individual and include the extended family and community.

\section{Limitations}

Retrospective observational hospital data presents challenges for cost analysis. Costs are based on activity and researchers must determine reasons for low or no activity. Where there was a priori knowledge of missing dialysis attendance for DxMoC4 and 5 (nonignorable missing values [53]) we made every effort to gather this information from other sources and link the data sets. We did not interpolate data nor impute costs as we could not be certain activity had occurred. This may 
Table 8 Mean annual costs for Aboriginal dialysis patients by included variables \$AUS2017

\begin{tabular}{|c|c|c|}
\hline Multivariate GLM regression for Aboriginal people with included variables & Marginal differences $(95 \% \mathrm{Cl})$ & $P$ value \\
\hline Constant & $\$ 25797(\$ 24793$ to $\$ 26801)$ & $<0.001$ \\
\hline Annual time in model & $\$ 39189(\$ 34558$ to $\$ 43819)$ & $<0.001$ \\
\hline \multicolumn{3}{|l|}{ Gender } \\
\hline Male & $\$ 2594$ (\$477 to \$4 712) & 0.016 \\
\hline \multicolumn{3}{|l|}{ Region } \\
\hline Top End (vs Central Australia) & $-\$ 5578(-\$ 7943$ to $-\$ 3214)$ & $<0.001$ \\
\hline \multicolumn{3}{|l|}{ Residence Pre RRT } \\
\hline Urban & Reference & \\
\hline Remote & $\$ 5451$ (\$754 to $\$ 10076)$ & 0.023 \\
\hline Very remote & $\$ 4777(\$ 1312$ to $\$ 8243)$ & 0.007 \\
\hline Remote border communities & $\$ 16594$ (\$2 605 to $\$ 30584)$ & 0.020 \\
\hline \multicolumn{3}{|l|}{ Admission age } \\
\hline$<30 y r s$ & $\$ 9405(\$ 2950$ to $\$ 15860)$ & 0.004 \\
\hline 30-39yrs & $\$ 13381$ (\$8 773 to $\$ 17989)$ & $<0.001$ \\
\hline 40-49yrs & $\$ 3977(\$ 1506$ to $\$ 6844)$ & 0.002 \\
\hline $50-59 y r s$ & Reference & \\
\hline $60-69 y r s$ & $\$ 1442(-\$ 1204$ to $\$ 4090)$ & 0.285 \\
\hline$>70 y r s$ & $\$ 1213(-\$ 4129$ to $\$ 6556)$ & 0.656 \\
\hline \multicolumn{3}{|l|}{ Time on dialysis } \\
\hline$<12$ mths & Reference & \\
\hline $1-2$ yrs & $-\$ 9707(-\$ 14288$ to $-\$ 5127)$ & $<0.001$ \\
\hline $2-3 y r s$ & $-\$ 11548(-\$ 16750$ to $-\$ 6345)$ & $<0.001$ \\
\hline $3-4 y r s$ & $-\$ 10524(-\$ 16291$ to $-\$ 4757)$ & $<0.001$ \\
\hline $4-5 y r s$ & $-\$ 14628(-\$ 20021$ to $-\$ 9234)$ & $<0.001$ \\
\hline$>5 y r s$ & $-\$ 13951(-\$ 18819$ to $-\$ 9083)$ & $<0.001$ \\
\hline \multicolumn{3}{|l|}{ Comorbid conditions } \\
\hline Diabetes (vs no diabetes) & $\$ 4614(\$ 1380$ to $\$ 7847)$ & 0.005 \\
\hline Cardiac (vs no cardiac) & $\$ 8632$ (\$6 371 to $\$ 10892)$ & $<0.001$ \\
\hline Vascular (vs no vascular) & $\$ 11930(\$ 9524$ to $\$ 14336)$ & $<0.001$ \\
\hline \multicolumn{3}{|l|}{ DxMoC } \\
\hline Incentre DxMoC0 & $\$ 4702$ (\$742 to \$8 662) & 0.020 \\
\hline Urban DxMoC1 & Reference & \\
\hline Rural DxMoC2 & $-\$ 5694(-\$ 8493$ to $-\$ 2894)$ & $<0.001$ \\
\hline Remote DxMoC3 & $-\$ 10818(-\$ 15468$ to $-\$ 6167)$ & $<0.001$ \\
\hline Remote CC DxMoC4 & $-\$ 15125(-\$ 18561$ to $-\$ 11689)$ & $<0.001$ \\
\hline SC HD DxMoC5 & $-\$ 8854(-\$ 13412$ to $-\$ 4296)$ & $<0.001$ \\
\hline SC PD DxMoC6 & $-\$ 2093(-\$ 6468$ to $\$ 2280)$ & 0.348 \\
\hline
\end{tabular}

under-estimate costs associated with dialysis treatments, although in those DxMoC where dialysis attendance was lower, hospitalisation activity and costs were higher. This supports the assumption that the lower observed activity and costs were not due to missing data. However we accept that this does not necessarily imply cause and effect and that there are other reasons for hospitalisations.
For instance admissions for infections, respiratory disorders and metabolic complications also rated highly. In addition, a local study found some remote residing patients voluntarily move to urban areas as their health needs increase [24] and we acknowledge clinician and patient self-selection may limit access of frail and complex patients (who are more likely to be hospitalised) to 
Table 9 Top three discharge diagnoses for each DxMoC (n (\%)), cost weights per episode aggregated and averaged

\begin{tabular}{|c|c|c|c|c|c|c|c|c|c|}
\hline $\begin{array}{l}\text { AR- } \\
\text { DRG }\end{array}$ & AR-DRG Description & $\begin{array}{l}\text { Cost } \\
\text { weight }\end{array}$ & DxMoCo & DxMoC1 & DxMoC2 & DxMoC3 & DxMoC4 & DxMoC5 & DxMoC6 \\
\hline L65B & $\begin{array}{l}\text { Kidney and Urinary Tract Signs and Symptoms W/O } \\
\text { Catastrophic or Severe CC }\end{array}$ & $\$ 2,758$ & $\begin{array}{l}277 \\
(15 \%)\end{array}$ & $\begin{array}{l}2036 \\
(18 \%)\end{array}$ & $90(5 \%)$ & $6(4 \%)$ & $47(13 \%)$ & $23(5 \%)$ & \\
\hline L65A & $\begin{array}{l}\text { Kidney and Urinary Tract Signs and Symptoms W } \\
\text { Catastrophic or Severe CC }\end{array}$ & $\$ 7,246$ & $\begin{array}{l}222 \\
(12 \%)\end{array}$ & $979(9 \%)$ & & & & & \\
\hline L67A & $\begin{array}{l}\text { Urinary Stones and Obstruction W Catastrophic or } \\
\text { Severe CC }\end{array}$ & $\$ 9,985$ & & & & & & & $\begin{array}{l}104 \\
(11 \%)\end{array}$ \\
\hline K62B & $\begin{array}{l}\text { Miscellaneous Metabolic Disorders W/O Catastrophic } \\
\text { or Severe CC }\end{array}$ & $\$ 4,691$ & & $355(3 \%)$ & & & & & \\
\hline $\mathrm{E} 62 \mathrm{~B}$ & $\begin{array}{l}\text { Respiratory Infections/Inflammations W Severe or } \\
\text { Moderate CC }\end{array}$ & $\$ 6,917$ & & & $99(6 \%)$ & $5(3 \%)$ & & & \\
\hline Z64A & Other Factors Influencing Health Status & $\$ 4,875$ & & & $97(6 \%)$ & & & & \\
\hline L60C & Kidney Failure W/O Catastrophic or Severe CC & $\$ 3,970$ & $95(5 \%)$ & & & & & & \\
\hline T64B & $\begin{array}{l}\text { Other Infectious and Parasitic Diseases W Severe or } \\
\text { Moderate CC }\end{array}$ & $\$ 9,167$ & & & & & & $60(12 \%)$ & \\
\hline L67B & $\begin{array}{l}\text { Other Kidney and Urinary Tract Disorders W/O } \\
\text { Catastrophic or Severe CC }\end{array}$ & $\$ 4,563$ & & & & & & & $57(6 \%)$ \\
\hline L09A & $\begin{array}{l}\text { Other Procedures for Kidney and Urinary Tract } \\
\text { Disorders W Cat CC }\end{array}$ & $\$ 29,964$ & & & & & & & $51(5 \%)$ \\
\hline F74Z & Chest Pain & $\$ 5,326$ & & & & & $26(7 \%)$ & & \\
\hline G66Z & Abdominal Pain or Mesenteric Adenitis & $\$ 2,378$ & & & & & $16(5 \%)$ & & \\
\hline F75B & Other Circulatory Disorders W Severe or Moderate CC & $\$ 6,168$ & & & & & & $16(3 \%)$ & \\
\hline E65B & $\begin{array}{l}\text { Chronic Obstructive Airways Disease W/O Catastrophic } \\
\text { CC }\end{array}$ & $\$ 5,886$ & & & & $10(6 \%)$ & & & \\
\hline \multicolumn{3}{|c|}{ Average cost per admission -Top 3 admissions aggregated } & $\$ 4,629$ & $\$ 4,143$ & $\$ 4,916$ & $\$ 5,238$ & $\$ 3,440$ & $\$ 7,193$ & $\$ 13,334$ \\
\hline
\end{tabular}

remote models of care, particularly where there is limited facility capacity and waiting lists exist.

\section{Conclusion}

Aboriginal patients and communities have long advocated for services closer to home, arguing for equitable and accessible services and pointing to literature documenting the psychosocial and economic imposts of relocation [54-58]. A reluctance to establish dialysis services in remote areas can be understood, given the increased resources associated with service delivery logistics and initial infrastructure expenditure. Concerns also exist regarding the quality of care available for remote residing patients [59-61]. In the NT, this reluctance is coupled with the perception that the already high rates of hospitalisations experienced by Aboriginal people on RRT, would be exacerbated further by distance and limited access to tertiary and specialist services in remote areas, resulting in significant increases in health service costs [23, 24].

Our study however, demonstrates that the increased costs associated with remote dialysis service delivery are more than offset by reduced downstream health service use (hospital admissions, ED visits) and costs. Valid economic assessments necessitate a consideration of the broader impacts of treatment access (or lack of), such as requirement for community infrastructure, logistics and cost of relocation, and importantly, the challenges faced by patients.

It is critical that these factors are not ignored in the design of models of care. The shaping of equitable and accessible service delivery models requires community consultation and consumer input as well as an examination of the full cost impacts of different dialysis models.

This study demonstrates the importance of understanding and interpreting the full implications of delivering dialysis services in different locations in order to accurately inform policy decisions. If health systems are to aim for efficient and effective models that meet the needs of the individual, a more holistic approach to the design process is required.

\section{Supplementary Information}

The online version contains supplementary material available at https://doi. org/10.1186/s12913-021-06612-z.

\section{Additional file 1 .}

\section{Acknowledgements}

The author would like to thank Dr Jeannie Devitt for her advice, guidance and assistance with manuscript preparation and Dr Martin Howell for his advice regarding statistical approaches. 


\section{Authors' contributions}

GG and KH designed the study. GG undertook the analysis with statistical advice and support from FB. KH and JC provided advice and guidance regarding methodological approaches. AC and PL advised on structure and content. GG drafted the initial manuscript. All authors critically reviewed the manuscript, contributed to the intellectual content and approved the final version of the manuscript.

\section{Funding}

The DxMoC study was funded through a National Health and Medical Research Council (NHMRC) grant (\#1092092). The corresponding author was supported with a National Health and Medical Research Council (NHMRC) Postgraduate Scholarship Grant (\#116826). JC was funded by an NHMRC Research Fellowship (\#1058244). All authors declared no competing interests.

\section{Availability of data and materials}

The data that supports the findings of this study are available from the Northern Territory Department of Health but restrictions apply to the availability of these data, which were conditions of the Ethics approval and so are not publicly available. Data are however available from the authors upon reasonable request and with permission of the Northern Territory Department of Health.

\section{Declarations}

\section{Ethics approval and consent to participate}

Ethics approval for the study was granted by the Joint Department of Health and Menzies School of Health Research Committee (HREC 2015-2334) and the Central Australian Health Research Ethics Committee (HREC 15-283). The study was reviewed and approved by their respective Aboriginal Ethics Sub Committees. The study was performed in accordance with the relevant guidelines and regulations of the relevant ethics committees and in accordance with the Declaration of Helsinki.

Informed consent was waived by the the Ethics committees that approved the study, the Joint Department of Health and Menzies School of Health Research Committee (HREC 2015-2334) and the Central Australian Health Research Ethics Committee (HREC 15-283).

\section{Consent for publication}

Not applicable.

\section{Competing interests}

The authors report no conflicts of interest.

\section{Author details}

${ }^{1}$ Menzies School of Health Research, Charles Darwin University, PO Box 41096, Casuarina, 0810 Darwin, Australia. ${ }^{2}$ Sydney School of Public Health, The University of Sydney, Sydney, Australia.

Received: 10 February 2021 Accepted: 7 June 2021

\section{Published online: 17 June 2021}

\section{References}

1. Cass A, Chadban S, Gallagher M, Howard K, Jones A, McDonald S, et al. The economic impact of end-stage kidney disease in Australia: Projections to 2020. Melbourne: Kidney Health Australia; 2010.

2. Klarenbach SW, Tonelli M, Chui B, Manns BJ. Economic evaluation of dialysis therapies. Nat Rev Nephrol. 2014;10(11):644-52. https://doi.org/10.1038/ nrneph.2014.145.

3. Walker R, Marshall MR, Morton RL, McFarlane P, Howard K. The costeffectiveness of contemporary home haemodialysis modalities compared with facility haemodialysis: a systematic review of full economic evaluations. Nephrology (Carlton, Vic). 2014;19(8):459-70. https:/doi.org/10.1111/nep.12269.

4. Komenda P, Gavaghan MB, Garfield SS, Poret AW, Sood MM. An economic assessment model for in-center, conventional home, and more frequent home hemodialysis. Kidney Int. 2012;81(3):307-13. https://doi.org/10.1038/ ki.2011.338.

5. Peeters P, Rublee $D$, Just PM, Joseph A. Analysis and interpretation of cost data in dialysis: review of Western European literature. Health policy (Amsterdam, Netherlands). 2000;54(3):209-27. https://doi.org/10.1016/s01688510(00)00112-3
6. Just PM, Riella MC, Tschosik EA, Noe LL, Bhattacharyya SK, de Charro F. Economic evaluations of dialysis treatment modalities. Health Policy (Amsterdam, Netherlands). 2008;86(2-3):163-80. https://doi.org/10.1016/j.hea Ithpol.2007.12.004.

7. Howell M, Walker RC, Howard K. Cost effectiveness of dialysis modalities: a systematic review of economic evaluations. Appl Health Econ Health Policy. 2019;17(3):315-30. https://doi.org/10.1007/s40258-018-00455-2.

8. Health Policy Analysis. NSW Dialysis Costing Studies. Sydney: NSW Department of Health; 2009.

9. Howard K, Salkeld G, White S, McDonald S, Chadban S, Craig JC, et al. The cost-effectiveness of increasing kidney transplantation and home-based dialysis. Nephrology (Carlton, Vic). 2009;14(1):123-32. https://doi.org/1 0.1111/j.1440-1797.2008.01073.x.

10. Karopadi AN, Mason G, Rettore E, Ronco C. Cost of peritoneal dialysis and haemodialysis across the world. Nephrol Dial Transplant. 2013;28(10):255369. https://doi.org/10.1093/ndt/gft214.

11. Liu FX, Treharne C, Culleton B, Crowe L, Arici M. The financial impact of increasing home-based high dose haemodialysis and peritoneal dialysis. BMC Nephrol. 2014;15(1):161. https://doi.org/10.1186/1471-2369-15-161.

12. ANZDATA Registry. 43rd Report, Chap. 4: Haemodialysis. Adelaide: Australia and New Zealand Dialysis and Transplant Registry. 2020.

13. Wong CKH, Chen J, Fung SKS, Mok MMY, Cheng YL, Kong I, et al. Direct and indirect costs of end-stage renal disease patients in the first and second years after initiation of nocturnal home haemodialysis, hospital haemodialysis and peritoneal dialysis. Nephrol Dial Transplant. 2019;34(9): 1565-76. https://doi.org/10.1093/ndt/gfy395.

14. Quinn RR, Ravani P, Zhang X, Garg AX, Blake PG, Austin PC, et al. Impact of modality choice on rates of hospitalization in patients eligible for both peritoneal dialysis and hemodialysis. Peritoneal dialysis international: journal of the International Society for Peritoneal Dialysis. 2014;34(1):41-8. https:// doi.org/10.3747/pdi.2012.00257

15. Rogers NM, Lawton PD, Jose MD. Kidney transplant outcomes in the indigenous population in the Northern Territory of Australia. Transplantation. 2006;82(7):882-6. https://doi.org/10.1097/01.tp.0000232439.88527.49.

16. Habach G, Bloembergen WE, Mauger EA, Wolfe RA, Port FK. Hospitalization among United States dialysis patients: Hemodialysis versus peritoneal dialysis. J Am Soc Nephrol. 1995;5(11):1940-8.

17. Beaudry A, Ferguson TW, Rigatto C, Tangri N, Dumanski S, Komenda P. Cost of Dialysis Therapy by Modality in Manitoba. Clin J Am Soc Nephrol. 2018; 13(8):1197-203. https://doi.org/10.2215/CJN.10180917.

18. Ferguson TW, Zacharias J, Walker SR, Collister D, Rigatto C, Tangri N, et al. An Economic Assessment Model of Rural and Remote Satellite Hemodialysis Units. PLoS ONE. 2015;10(8):e0135587. https://doi.org/10.1371/journal.pone. 0135587.

19. Gorham G, Howard K, Zhao Y, Ahmed AMS, Lawton PD, Sajiv C, et al. Cost of dialysis therapies in rural and remote Australia - a micro-costing analysis. BMC Nephrol. 2019;20(1):231. https://doi.org/10.1186/s12882-019-1421-z.

20. ANZDATA Registry. 42nd Report, Chap. 10: End stage kidney disease in Aboriginal and Torres Strait Islander Australians. Adelaide: Australia and New Zealand Dialysis and Transplant Registry; 2020.

21. Australian Institute of Health and Welfare. Chronic kidney disease: regional variation in Australia. Canberra: Australian Government; 2013.

22. Gorham G, Majoni S, Lawton P, Brown S, Dube B, Conlon T, et al. Interesting times: evolution of dialysis in Australia's Northern Territory (1980-2014). Renal Soc Australasia J. 2018;14(3):108-16.

23. Zhao Y, Wright J, Guthridge S, Lawton P. The relationship between number of primary health care visits and hospitalisations: evidence from linked clinic and hospital data for remote Indigenous Australians. BMC Health Serv Res. 2013;13(1):466. https://doi.org/10.1186/1472-6963-13-466.

24. Malyon R, Zhao Y, Oates B. Differences in the cost of admitted patient care for Indigenous people and people from remote locations. Austr Health Rev. 2013;37(1):26-31. https://doi.org/10.1071/AH11115.

25. Wilson R, Krefting L, Sutcliffe P, Van Bussel L. Native Canadians relocating for renal dialysis. Psychosocial and cultural issues. Can Fam Physician. 1994;40: 1934-41.

26. Lavoie JG, Kaufert J, Browne AJ, Mah S, O'Neil JD, Sinclair S, et al. Negotiating barriers, navigating the maze: First Nation peoples' experience of medical relocation. Canadian Publ Admin. 2015;58(2):295-314. https://doi.org/10.1111/capa.12111.

27. Gorham G. Prevention and treatment options for renal disease in the Northern Territory (with particular reference to the Barkly region). Darwin: Cooperative Research Centre for Aboriginal and Tropical Health; 2003. 
28. Devitt J, McMasters A. 'They don't last long': Aboriginal patient experience of end-stage renal disease in Central Australia. Nephrology. 1998:4:S111-7.

29. Anderson K, Yeates K, Cunningham J, Devitt J, Cass A. They really want to go back home, they hate it here: the importance of place in Canadian health professionals' views on the barriers facing Aboriginal patients accessing kidney transplants. Health Place. 2009;15(1):390-3. https://doi. org/10.1016/j.healthplace.2008.03.002.

30. Anderson K, Cunningham J, Devitt J, Cass A. The IMPAKT study: using qualitative research to explore the impact of end-stage kidney disease and its treatments on aboriginal and Torres Strait Islander Australians. Kidney Int Suppl. 2013;3(2):223-6. https://doi.org/10.1038/kisup.2013.19.

31. Dixit SK, Sambasivan M. A review of the Australian healthcare system: A policy perspective. SAGE Open Med. 2018;6:2050312118769211. https://doi. org/10.1177/2050312118769211.

32. IPHA. The AR-DRG classification system. https://www.ihpa.gov.au/admitted-a cute-care/ar-drg-classification-system. 2018.

33. Australian Statistical Geography Standard (ASGS) [database on the Internet]. ABS. 2016. Available from: Australian Statistical Geography Standard (ASGS) Volume5 - Remoteness Structure (cat. no. 1270.0.55.005) publication. Accessed: 22 Aug 2018

34. Census [database on the Internet]. Australian Government. 2016. Available from: www.censusdata.abs.gov.au/census_services/getproduct/census/2016/ .../UCL714001. Accessed 22 Aug 2018

35. Gorham G, Howard K, Togni S, Lawton P, Hughes J, Majoni SW, et al. Economic and quality of care evaluation of dialysis service models in remote Australia: protocol for a mixed methods study. BMC Health Serv Res. 2017;17(1):320. https://doi.org/10.1186/s12913-017-2273-5.

36. PWC. Home Delivered Dialysis Costing study to inform the National Efficient Price 2015: Final Report to Independent Hospital Pricing Authority. Costing study. Sydney: Pricewaterhouse Coopers;2015. 11 November 2014.

37. Kidney Strategic Clinical Network. Annual Kidney Care Report: Prevalence of severe kidney disease and use of dialysis and transplantation across Alberta from 2004-2013. Alberta: Alberta Health Services; 2015.

38. Ashton T, Marshall MR. The organization and financing of dialysis and kidney transplantation services in New Zealand. Int J Health Care Finance Econ. 2007;7(4):233-52. https://doi.org/10.1007/s10754-007-9023-x

39. Lee H, Manns B, Taub K, Ghali WA, Dean S, Johnson D, et al. Cost analysis of ongoing care of patients with end-stage renal disease: the impact of dialysis modality and dialysis access. Am J Kidney Dis. 2002;40(3):611-22. https://doi. org/10.1053/ajkd.2002.34924.

40. Baboolal K, McEwan P, Sondhi S, Spiewanowski P, Wechowski J, Wilson K. The cost of renal dialysis in a UK setting-a multicentre study. Nephrol Dial Transplant. 2008;23(6):1982-9. https://doi.org/10.1093/ndt/gfm870.

41. Belotti F, Deb P, Manning WG, Norton EC. twopm: Two-part models. Stata J. 2015;15(1):3-20.

42. Bhaskaran $\mathrm{K}$, Smeeth $\mathrm{L}$. What is the difference between missing completely at random and missing at random? Int J Epidemiol. 2014;43(4):1336-9.

43. Buntin MB, Zaslavsky AM. Too much ado about two-part models and transformation? Comparing methods of modeling Medicare expenditures. J Health Econ. 2004;23(3):525-42. https://doi.org/10.1016/j.jhealeco.2003.10.005

44. Deb P, Norton EC, Manning WG. Health econometrics using Stata. College Station: Stata Press; 2017.

45. Komenda P, Copland M, Makwana J, Djurdjev O, Sood MM, Levin A. The cost of starting and maintaining a large home hemodialysis program. Kidney Int. 2010:77(11):1039-45. https://doi.org/10.1038/ki.2010.37.

46. Chow E, Wong H, Hahn-Goldberg S, Chan CT, Morra D. Inpatient and emergent resource use of patients on dialysis at an academic medical center. Nephron. 2014;126(3):124-7. https://doi.org/10.1159/000360541.

47. Li B, Cairns J, Fotheringham J, Ravanan R, Group AS. Predicting hospital costs for patients receiving renal replacement therapy to inform an economic evaluation. Eur J Health Econ. 2016;17(6):659-68. https://doi.org/1 0.1007/s10198-015-0705-X.

48. Albuquerque de Almeida F, Al MJ, Koymans R, Riistama J, Pauws S, Severens $J$. Impact of hospitalisation on health-related quality of life in patients with chronic heart failure. Health Qual Life Outcomes. 2020;18(1):262. https://doi. org/10.1186/s12955-020-01508-8.

49. /Lim WH, Boudville N, McDonald SP, Gorham G, Johnson DW, Jose M. Remote indigenous peritoneal dialysis patients have higher risk of peritonitis, technique failure, all-cause and peritonitis-related mortality. Nephrol Dial Transplant. 2011;26(10):3366-72. https://doi.org/10.1093/ndt/ gfr070.
50. Hildebrand A, Komenda P, Miller L, Rigatto C, Verrelli M, Sood AR, et al. Peritonitis and exit site infections in First Nations patients on peritoneal dialysis. Clin J Am Soc Nephrol. 2010;5(11):1988-95. https://doi.org/10.2215/ CJN.04170510.

51. Anderson K, Devitt J, Cunningham J, Preece C, Jardine M, Cass A. If you can't comply with dialysis, how do you expect me to trust you with transplantation? Australian nephrologists' views on indigenous Australians' 'non-compliance' and their suitability for kidney transplantation. Int J Equity Health. 2012;11:21. https://doi.org/10.1186/1475-9276-11-21.

52. Smyth W, Hartig V, Hayes M, Manickam V. Patients' adherence to aspects of haemodialysis regimens in tropical north Queensland. Australia J Ren Care. 2015;41(2):110-8. https://doi.org/10.1111/jorc.12108.

53. Pohl S, Becker B. Performance of missing data approaches under nonignorable missing data conditions. Methodology. 2020;16(2):147-65. https://doi.org/10.5964/meth.2805.

54. McGrath P. Exploring Aboriginal people's experience of relocation for treatment during end-of-life care. Int J Palliat Nurs. 2006;12(3):102-8. https:// doi.org/10.12968/ijpn.2006.12.3.20692.

55. Lavoie J, Forget E, Rowe G, Dahl M. The leaving for the city project (medical relocation project phase 2): Final report. Winnipeg: University of Manitoba; 2009

56. Devitt J, McMasters A. Living on Medicine: A cultural study of end-stage renal disease among Aboriginal people. Alice Springs Northern Territory: IAD Press; 1998.

57. Kelly J, Dwyer J, Willis E, Pekarsky B. Travelling to the city for hospital care: access factors in country Aboriginal patient journeys. Australian J Rural Health. 2014;22(3):109-13. https://doi.org/10.1111/ajr.12094.

58. Rivalland P. 'Its more than machines and medicine, they should understand there's a Yanangu Way'. Summary Report. Darwin: Cooperative Research Centre for Aboriginal Health; 2006.

59. Tonelli M, Hemmelgarn B, Culleton B, Klarenbach S, Gill JS, Wiebe N, et al. Mortality of Canadians treated by peritoneal dialysis in remote locations. Kidney Int. 2007;72(8):1023-8. https://doi.org/10.1038/sj.ki.5002443.

60. Gray NA, Dent H, McDonald SP. Renal replacement therapy in rural and urban Australia. Nephrol Dial Transplant. 2012;27(5):2069-76. https://doi. org/10.1093/ndt/gfr584.

61. Thompson S, Bello A, Wiebe N, Manns B, Hemmelgarn B, Klarenbach S, et al. Quality-of-care indicators among remote-dwelling hemodialysis patients: a cohort study. Am J Kidney Dis. 2013;62(2):295-303. https://doi.org/10.1053/ j.ajkd.2013.01.021.

\section{Publisher's Note}

Springer Nature remains neutral with regard to jurisdictional claims in published maps and institutional affiliations.

Ready to submit your research? Choose BMC and benefit from:

- fast, convenient online submission

- thorough peer review by experienced researchers in your field

- rapid publication on acceptance

- support for research data, including large and complex data types

- gold Open Access which fosters wider collaboration and increased citations

- maximum visibility for your research: over $100 \mathrm{M}$ website views per year

At BMC, research is always in progress.

Learn more biomedcentral.com/submission 